\title{
SYSTEMATIC OZONE AND SOLAR UV MEASUREMENTS IN THE OBSERVATORIO ATMOSFÉRICO DE LA PATAGONIA AUSTRAL, ARGENTINA
}

http://dx.doi.org/10.4322/apa.2014.089

\section{Elian Wolfram ${ }^{1}$, Jacobo Salvador ${ }^{1}$, Facundo Orte ${ }^{1}$, Raul D’Elia $^{1}$, Eduardo.Quel', Claudio Casiccia², Felix Zamorano², Neusa Paes Leme ${ }^{3}$}

\author{
${ }^{1}$ Centro de Investigaciones en Láseres y Aplicaciones, CEILAP-UNIDEF (MINDEF-CONICET), \\ UMI-IFAECI-CNRS-3351, Villa Martelli, Argentina \\ ${ }^{2}$ Universidad de Magallanes - UMAG, Punta Arenas, Chile \\ ${ }^{3}$ Instituto Nacional de Pesquisas Espaciais - INPE, Natal, Brazil

$$
\text { *e-mail: ewolfram@gmail.com }
$$

\begin{abstract}
The depletion of the polar ozone layer is one of the strongest anthropogenic signals in the Earth system. Subpolar regions in the southern part of South America are affected by this phenomenon, covered sometimes by air masses with less ozone than normal with the corresponding UV enhancements at ground surface. Motivated by these atmospheric events, Argentina and Chile with the financial support of JICA has joined scientific efforts to develop UVO Patagonia project. The Observatorio Atmosférico de la Patagonia Austral is located in South Patagonia $\left(51^{\circ} 55^{\prime} \mathrm{S}, 6^{\circ} 14^{\prime} \mathrm{W}\right)$, in the subpolar region and it is a convenient monitoring site of the atmosphere in the Southern Hemisphere. In this experimental site a differential absorption lidar instrument for the measurement of ozone vertical distribution is operative. The altitude range of the ozone measurement is $14-45 \mathrm{~km}$, which provides the opportunity to monitor the turbulences due to the passage of stratospheric polar air over Río Gallegos. Systematic stratospheric ozone profile measurement has been carried on in this experimental site since 2005. We identified three major perturbations of the ozone hole over the stratospheric ozone profile in Rí Gallegos. Approach of polar vortex during late winter, overpass of ozone hole in middle spring and dilution process during late spring change the shape and content of stratospheric ozone profile and as a consequence the solar UV. Solar surface irradiance and total ozone content were measured with a Brewer spectraphotometer and moderate narrow band radiometer GUV-541 deployed in the Río Gallegos experimental site.
\end{abstract}

Keywords: Lidar, Ozone, UV Radiation, Polar Vortex

\section{Introduction}

Nowadays we have strong evidence that human activities linked to industrialized processes have perturbed the natural balance of atmosphere composition (WMO, 2011). This fact has produced global scale issues like ozone depletion around the globe. The stronger manifestation of this phenomenon is the Antarctic ozone depletion today well known as ozone hole (Farman et al., 1985). Subpolar regions such as Patagonia in Argentina and Chile, in the southern part of South America are affected by this phenomenon covered sometimes by air masses with less ozone than normal with the corresponding UV enhancements at ground surface.
During the past twenty years, this phenomenon has varied in size and with respect to the minimum total ozone value within the Polar Regions. Dynamical processes into the stratosphere cause changes in the size and shape of the polar vortex, which elongates together with the ozone hole that is contained within the vortex. The daily movement of the vortex combined with this particular shape induces overpasses of the ozone hole over the continental part of South America. In these situations cities with a large number of inhabitants like Río Gallegos (515' 5 , 69 $14^{\prime} \mathrm{W}$ ) are under the influence of the ozone hole or near its border, 
causing an increase of solar UV radiation at these places (Pazmiño et al., 2005; Wolfram et al., 2009).

Motivated by these atmospheric events, Argentine, Chilean Japanese and French researchers cooperated to conduct atmospheric studies using remote sensing instrument. These instruments were installed in the Atmospheric Observatory of Southern Patagonia (Observatorio Atmosférico de la Patagonia Austral, OAPA). In this work, we made a brief introduction to the measurement techniques of ozone and UV radiation held in this remote sensing site, and present, as an example, the same typical measurement.

\section{Materials and Methods}

\section{Site description}

The Atmospheric Observatory of Southern Patagonia, (Observatorio Atmosférico de la Patagonia Austral, OAPA), is part of Lidar Division of CEILAP (CITEDEF-CONICET). Río Gallegos city is located in South Patagonia (51 55'S, $69^{\circ} 14^{\prime} \mathrm{W}$ ). Since June 2005, a shelter with several lidar instruments developed in collaboration with the French Aeronomy Service (CNRS, Centre National de la Recherche Scientifique) was deployed in this Patagonian city, $2600 \mathrm{~km}$ distant from Buenos Aires. During 2005 and 2007, with the financial support of JICA (Japanese International Cooperation Agency), was held the SOLAR campaign (www.division-lidar.com.ar) (Wolfram, et al., 2006). The principal objective of this campaign was to study the ozone layer when the polar vortex crosses over the continental part of Argentina, in South America.

After the SOLAR campaign, different projects were developed with financial support of JICA (Japan International Cooperation Agency) in partnership with researchers from Chile, France and Japan. The main objectives of these projects are focused in the observation of atmospheric parameter with lidar remote sensing techniques, especially the measurement of stratospheric ozone profiles using differential absorption lidar technique. Río Gallegos is located in the surf zone of polar vortex, making it a very interesting place to observe the evolution and perturbation that the ozone hole produces on the stratospheric ozone profile.
The OAPA has currently a different instrument dedicated to the observation of gases $\left(\mathrm{O}_{3}\right.$ and $\left.\mathrm{NO}_{2}\right)$ and particles (i.e. aerosols) in the atmosphere, such as solar radiation (UV and visible). Several kinds of techniques are used to monitor ozone, like differential absorption lidar (DIAL) for determination of stratospheric ozone profiles and different radiometers, as SAOZ and Brewer for total ozone column measurements. In this paper we only focused in DIAL ozone products and solar UV index measured with GUV radiometer.

\section{DIAL Instrument Description}

The DIAL technique is a well-established technique for the ozone profile measurement, as is demonstrated by the large number of publications about the subject. The DIAL technique uses $\mathrm{XeCl}$ excimer laser emission at $308 \mathrm{~nm}$ for absorbed wavelength and the $355 \mathrm{~nm}$ third harmonic radiation of Nd-YAG laser for the reference wavelength. Both laser pulses are sequentially sending to the atmosphere. Six channels are used for the signal receival, four of them for the detection of elastically backscattered signal of the emitted wavelengths (high energy mode for the higher altitude ranges, attenuated energy for the lower ranges) and two corresponding to the first Stokes nitrogen Raman of the emitted wavelengths.

The optical receiving system consists of four parabolic telescopes (f/2) $50 \mathrm{~cm}$ diameter. Four quartz optical fibers are placed at the focal points of the telescopes and come together vertically to form the entrance slit of the spectrometer. These transmit the backscatter radiation from the atmosphere to an optical analyzer device, which includes optics for image formation, a chopper to prevent the saturation of the photomultipliers and a spectrometer designed to separate/split the different wavelengths to be detected. A fundamental part of the spectrometer is a Jobin Yvon holographic grating with 3600 lines per millimeter characterized by $40 \%$ efficiency in the $150-450 \mathrm{~nm}$ spectral range. It separates 5 wavelengths, 4 of which are used for obtaining ozone profiles and the combination of the fifth wavelength $(347 \mathrm{~nm})$ with one of the previous ones $(332 \mathrm{~nm})$ for obtaining profiles of water vapor in the troposphere. A full description of this DIAL system can be found in Wolfram et al. (2008). 


\section{GUV radiometer}

The multi-channel moderate-bandwidth GUV-541 have proven to be an acceptable solution for monitoring solar UV irradiance, a mix of UV spectroradiometer of very expensive and high maintenance, and broadband radiometers that provide only partial information because they cannot distinguish between changes in UV radiation caused by alterations in cloud cover and variations caused by changes in ozone amount. GUV filter radiometers, designed and manufactured by Biospherical Instruments Inc. The instruments provide measurements in five approximately $10 \mathrm{~nm}$ wide UV bands centered at $305,313,320,340$, and $380 \mathrm{~nm}$.

The synergy of UV irradiance measured with this instrument and radiative transfer model permits obtaining UV related products, like UV index or erythemal irradiance, and cloud optical depth, amongst others. In this work we present UV index measurement derived from GUV radiometer.

\section{Results}

The ozone observation with lidar in OAPA is conducted within two different measurements protocols: an intensive period between August and November each year, (late winter - spring time in the Southern Hemisphere), and routine measurement period for the rest of the year. During intensive measurement period which is coincident with the ozone hole development, the stratospheric ozone layer is monitored on average for 4 hours each time a clear night is available.

Total ozone column in Río Gallegos follows a seasonal variation over the year with minimum values around autumn (March-April) and maximum values during spring (September-October). Over this annual variability total ozone column presents big day to day variation. These rapid changes are caused by the approximation and overpass at Río Gallegos of polar air masses of air isolated from the middle latitude air by polar vortex.

The fluctuations on the total ozone column are clearly appreciated in Figure 1, where total ozone column measured by OMI/AURA instrument (blue line) are plotted from 2005 to 2009 . The white line is the climatologic monthly mean ozone column using multi sensor reanalysis (MSR) total ozone column from 1987- 2008 time period.

Stratospheric ozone profiles are measured with a Differential Absorption Lidar (DIAL). This instrument belongs to NDACC (Network for the Detection of Atmospheric Composition Change). Since 2005 this instrument has been

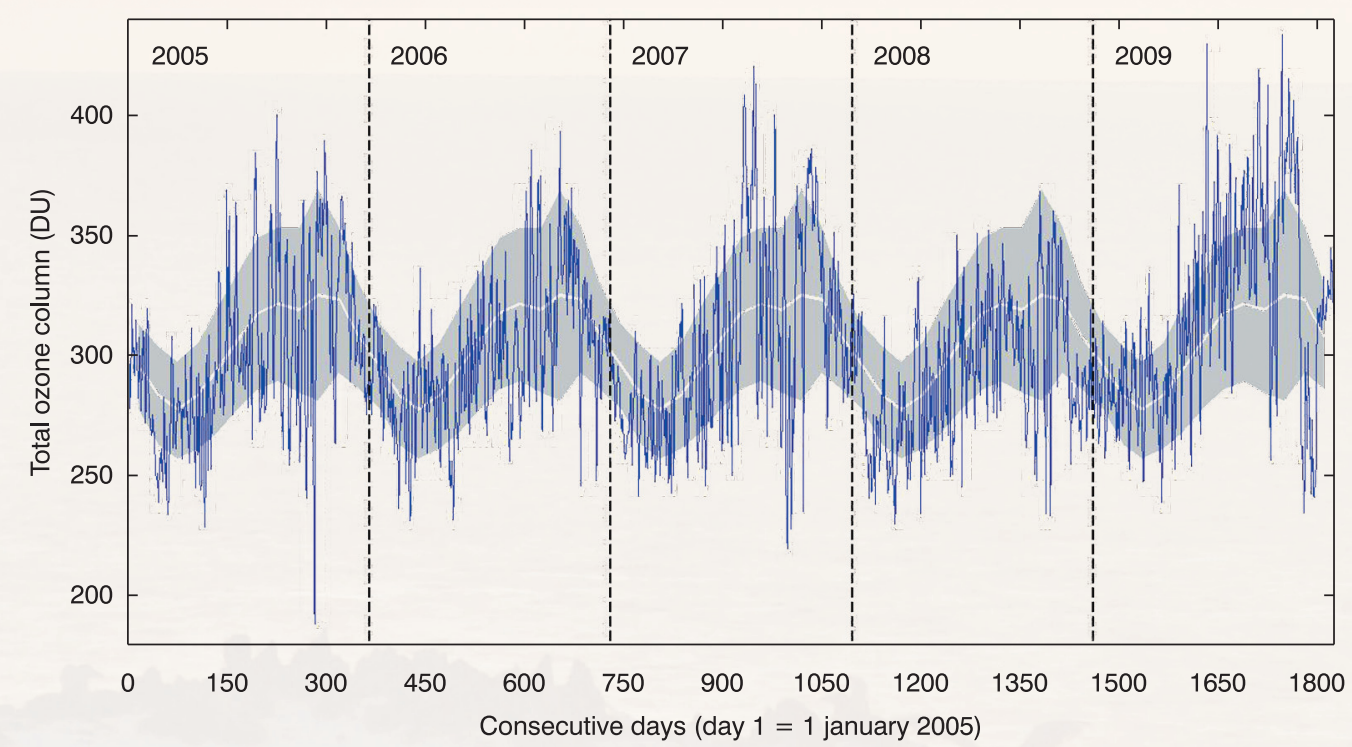

Figure 1. Time evolution of total ozone column over OAPA measured with OMI/NASA instrument (Blue Line). White line is the climatologic monthly mean ozone column using multisensor reanalysis (MSR) total ozone column from 1987- 2008 time period. Gray shadow area corresponds to +/- 1 standard deviation. 
monitoring ozone profiles in the stratosphere. Extreme ozone depletion has been measured as consequence of ozone hole passing over. Also, vortex dilution processes were measured in late spring-early summer.

The 2009 spring was a very special moment, because the polar vortex overpassed several times during October, and it was stagnant over continent in November, producing strong perturbation of the ozone profile as a consequence of the ozone hole located over Southern Patagonia. Figure 2 shows the DIAL ozone profile measured for mid November. The strong reduction over $20 \mathrm{~km}$ is clearly appreciated in comparison with the climatological profile of Fortuin \& Kelder (Fortuin \& Kelder, 1998) for this month and this latitude.

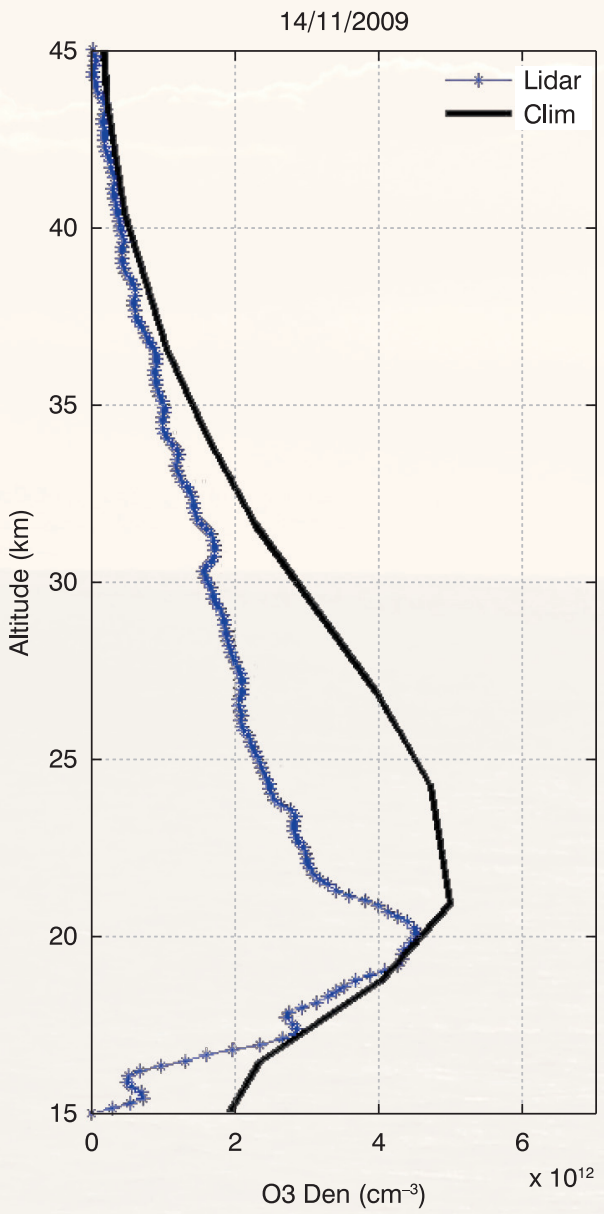

These events produce strong impact in the solar UV radiation that reach ground surface (UVI). UVI is measured with different radiometers and Brewer spectra photometer (SN 124) of INPE. Particularly on November 15 the UV index reach values as high as 13 despite the cloud cover present in Río Gallegos for this day. It produces an extreme solar sunbathing.

\section{Discussion and Conclusion}

The OAPA is an atmospheric laboratory that performs several kinds of atmospheric measurements in Río Gallegos, Southern Patagonia. Since June 2005 stratospheric ozone profiles and solar UV radiation have been measured among other atmospheric parameters. In this paper we reported

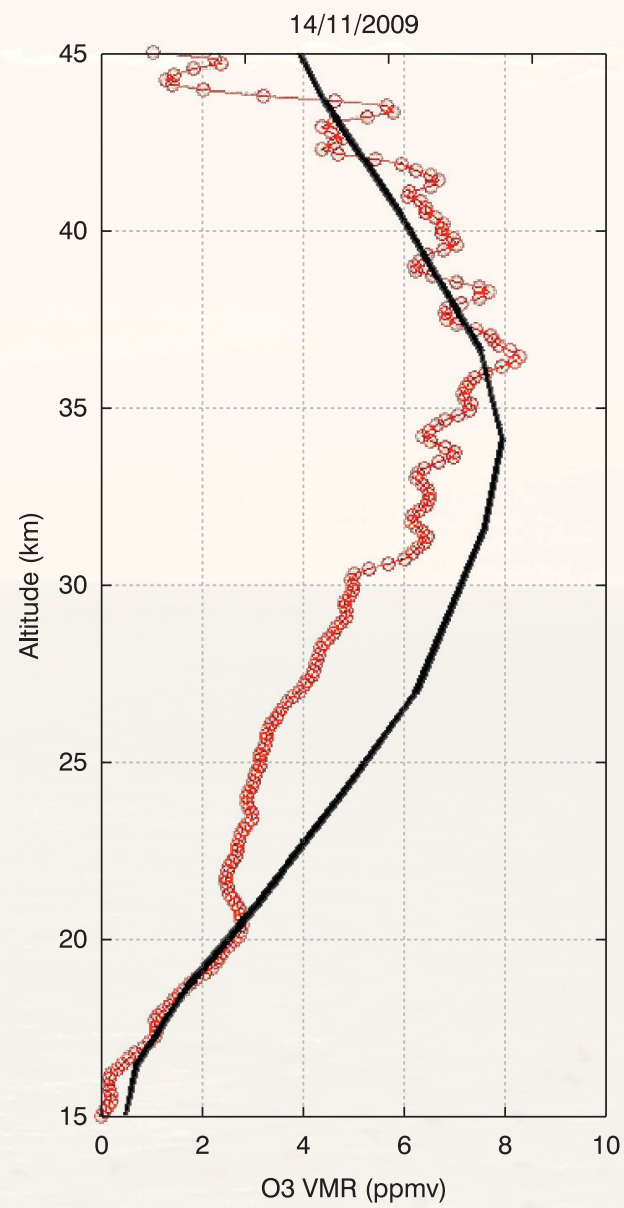

Figure 2. DIAL ozone profile on November 14, 2009. Blue line is the ozone number density (cm-3) (left panel, blue line) and ozone volume mixing ratio (ppmv) (right panel, red circles). For comparison of vertical ozone profile shape change, November climatologic Fortuin \& Kelder ozone profile is included (black line). 


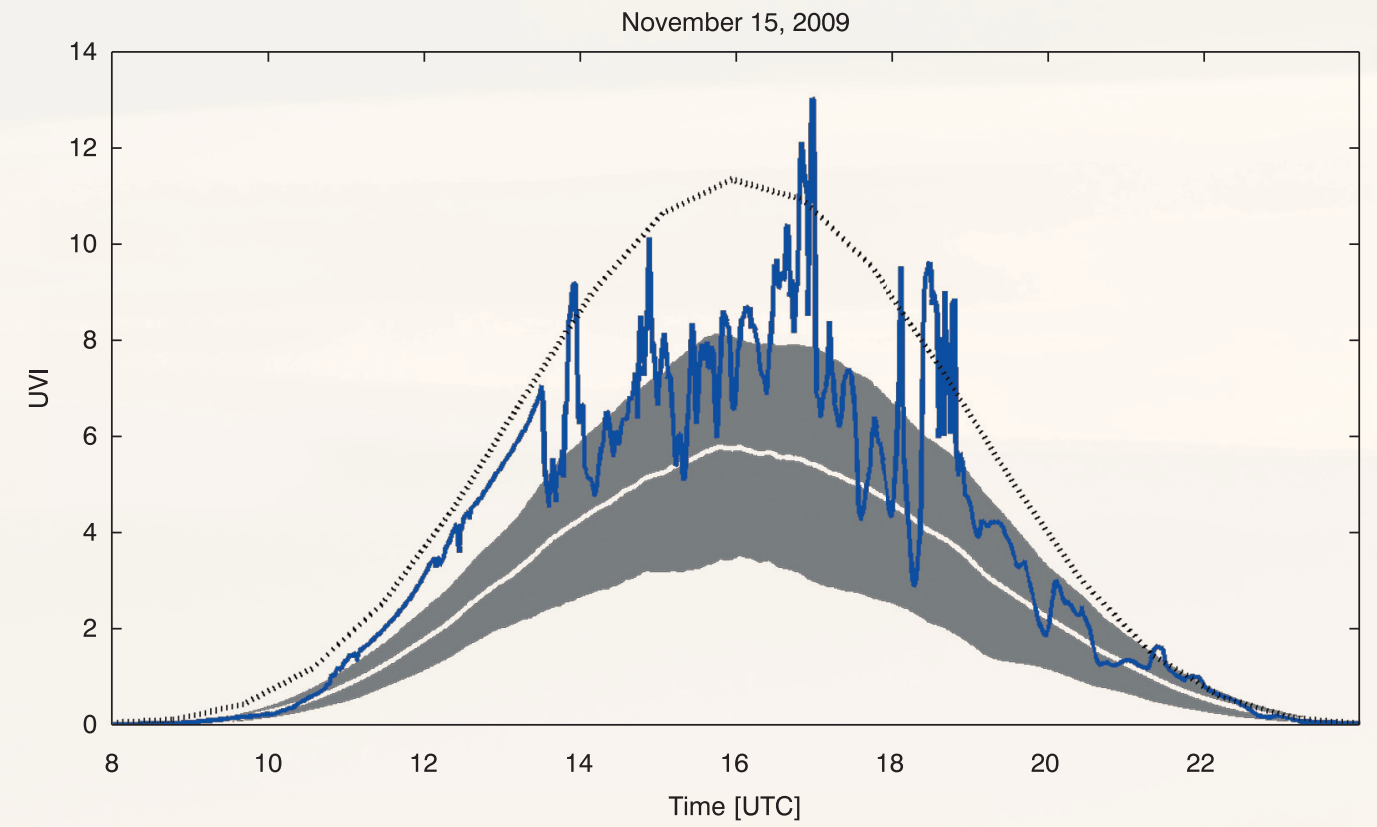

Figure 3. Time evolution of UV Index in Río Gallegos on November 15, 2009. The measurements were obtained with a GUV 541 and they are plotted in blue line. November monthly mean of UVI is shown in white line and the shadow grey area corresponds to +/- 1 SD. Modeled UVI for Nov. 15 is shown in dotted black line.

one example of differential absorption lidar measurement of stratosphere ozone number density in the 15 - $45 \mathrm{~km}$ range for a situation of ozone anomaly. Ozone hole overpass and vortex dilution are identified as examples of reduction and change in stratospheric ozone profiles. Also an extreme solar sunbathing which occurred in November 2009 is reported. We identified three major perturbations of the ozone hole over the stratospheric ozone profile in Río Gallegos: 1) approach of polar vortex during late winter, 2) overpass of ozone hole in mid spring and 3) dilution process during late spring that changes of the shape and content of stratospheric ozone profile and by consequences of the solar $\mathrm{UV}$ radiation that reaches the surface.

\section{Acknowledgments}

The authors would like to thank JICA (Japan International Cooperation Agency) for the financial support of $\mathrm{UVO}_{3}$
Patagonia Project; the CNRS, (Centre National de la Recherche Scientifique) for their collaboration in facilitating the shelter and part of the electronic instruments of DIAL. This work integrates the National Institute of Science and Technology Antarctic Environmental Research (INCTAPA) that receives scientific and financial support from the National Council for Research and Development (CNPq process: $\mathrm{n}^{\circ} 574018 / 2008-5$ ), the IPY Project ATMANTAR ( CNPq process: $n^{\circ}$ 52.0182/2006-5 ) and Carlos Chagas Research Support Foundation of the State of Rio de Janeiro (FAPERJ n ${ }^{\circ}$ E-16/170.023/2008) The authors also acknowledge the support of the Brazilian Ministries of Science, Technology and Innovation (MCTI), of Environment (MMA) and Inter-Ministry Commission for Sea Resources (CIRM). 


\section{References}

Farman, J.C.; Gardiner, B.G. \& Shanklin, J.D. (1985) Large losses of total ozone in Antarctica reveal seasonal CIOX/NOx interaction. Nature, 315: 207-210.

Fortuin, J.P.F. \& Kelder, H. (1998). An ozone climatology base on ozonesonde and satellite measurements, Journal of Geophysical Research, 103(31): 709-734.

Pazmiño, A.; Godin-Beekmann, S.; Ginzburg, M.; Bekki, S.; Hauchecorne, A.; Piacentini, R. \& Quel E. (2005). Impact of Antartic polar vortex occurrences on total ozone and UVB radiation at southern Argentinean and Antarctic stations during 1997-2003 period" Journal of Geophysical Research, 110(D03103): 1-13.

Wolfram E.; Salvador, J.; Pallotta, J.; D’Elia, R.; Otero, L.; Godin-Beeckmann, S.; Nakane, H. \& Quel, E. (2006). Solar Campaign: First Results Of Ozone Profile Measurements At Rio Gallegos, Argentina, Reviewed and Revised Papers Presented at the 23rd International Laser Radar Conference Editors Chikao Nagasawa, Nobuo Sugimoto, Part II 365-368.

Wolfram E. A.; Salvador, J.; D’Elia, R.; Casiccia, C.; Paes-Leme, N.; Pazmiño, A.; Porteneuve, J.; Godin-Beekman, S.; Nakane, H. \& Quel, E. J. (2008). New differential absorption lidar for stratospheric ozone monitoring in Patagonia, South Argentina, Journal of Optics, 10(10): 14-21.

Wolfram, E.; Salvador, J.; D’Elia, R. \& Quel, E. (2009). UV ground based measurements in Río Gallegos, Argentina. Current Problems in Atmospheric Radiation (IRS), p.1100351-354.

World Meteorological Organization - WMO (2011). Scientific Assessment of Ozone Depletion: 2010, Global Ozone Research and Monitoring Project-Report No. 52, 516 pp., Geneva, Switzerland.

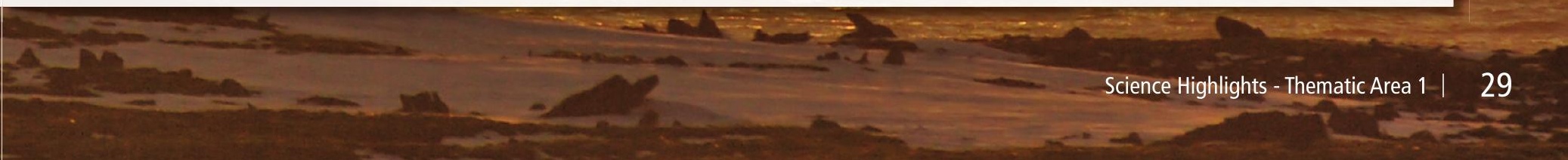

